Gut and Liver, Vol. 12, No. 1, January 2018, pp. 67-72

\title{
The Clinical Characteristics and Prognosis of Crohn's Disease in Korean Patients Showing Proximal Small Bowel Involvement: Results from the CONNECT Study
}

\author{
One Zoong Kim ${ }^{1}$, Dong Soo $\mathrm{Han}^{1}$, Chan Hyuk Park ${ }^{1}$, Chang Soo Eun ${ }^{1}$, You Sun Kim², Young-Ho Kim² , Jae Hee Cheon ${ }^{4}$, \\ Byong Duk Ye ${ }^{5}$, and Joo Sung Kim ${ }^{6}$ \\ ${ }^{1}$ Department of Internal Medicine, Hanyang University Guri Hospital, Guri, ${ }^{2}$ Department of Internal Medicine, Inje University College of \\ Medicine, ${ }^{3}$ Department of Internal Medicine, Sungkyunkwan University School of Medicine, ${ }^{4}$ Department of Internal Medicine and Institute of \\ Gastroenterology, Yonsei University College of Medicine, ${ }^{5}$ Department of Internal Medicine, Asan Medical Center, University of Ulsan College \\ of Medicine, and ${ }^{6}$ Department of Internal Medicine and Liver Research Institute, Seoul National University College of Medicine, Seoul, Korea
}

See editorial on page 3 .

Background/Aims: We aimed to evaluate the clinical characteristics and prognosis of Crohn's disease (CD) in patients who showed proximal small bowel involvement using a nationwide Korean CD cohort. Methods: We reviewed the data from a cohort of patients diagnosed with CD. The clinical outcomes of patients were evaluated according to the presence of proximal small bowel involvement. Results: Among 1,329 patients with CD for whom complete disease location data were available, 222 patients (16.7\%) showed involvement of the proximal small bowel. Compared to patients without proximal small bowel involvement, those with small bowel involvement were more likely to display stricturing behavior (19.8\% vs $12.7 \%, p=0.020)$. The surgery-free survival of patients who showed proximal small bowel involvement was inferior to that of patients without proximal small bowel involvement (10-year surgery-free survival: $58.4 \%$ vs $67.7 \%$, respectively, $p<0.001)$. Additionally, upper gastrointestinal involvement was more common in patients with proximal small bowel involvement than in those without involvement (odds ratio, 1.643; 95\% confidence interval, 1.008 to 2.677). Conclusions: Proximal small bowel involvement is a poor prognostic factor for the surgery-free survival of Korean patients with CD. Proximal small bowel involvement should be evaluated in patients with CD for predicting long-term clinical outcomes. (Gut Liver 2018;12:67-72)
Key Words: Crohn disease; Proximal small bowel; Jejunum; Prognosis; General surgery

\section{INTRODUCTION}

Crohn's disease (CD) is a chronic inflammatory disorder that can involve any part of the alimentary tract from the mouth to anus, although it involves frequently in the distal small intestine and proximal large bowel. ${ }^{1}$ Although proximal small bowel involvement is less common than distal small bowel or colonic involvement in $\mathrm{CD}$, it should be of concern because it is associated with a high risk of clinical relapse, including the need for abdominal surgery. ${ }^{2}$ Several studies have demonstrated that patients showing proximal small bowel involvement have clinical features distinct from those of patients without proximal small bowel involvement. ${ }^{2,3}$ In addition, different modalities for baseline evaluation and more sophisticated surveillance may be required for patients with proximal small bowel involvement. ${ }^{4}$ However, conclusions on the disease course and prognosis of $\mathrm{CD}$ have been primarily based on studies performed in Western countries. ${ }^{5,6}$ Currently, CD has become a global concern because of rapidly increasing incidence and prevalence in Asian Pacific region. $^{7-10}$

To better understand the prognosis of Korean patients with CD who showed proximal small bowel involvement, we evaluated the clinical characteristics and disease course, including the need for CD-related surgery, using data derived from the Crohn's Disease Clinical Network and Cohort (CONNECT) study. ${ }^{11,12}$ The

Correspondence to: Dong Soo Han

Department of Internal Medicine, Hanyang University Guri Hospital, Hanyang University College of Medicine, 153 Gyeongchun-ro, Guri 11923, Korea

Tel: +82-31-560-2226, Fax: +82-31-553-7369, E-mail: hands@hanyang.ac.kr

Received on October 11, 2016. Revised on March 7, 2017. Accepted on March 22, 2017. Published online August 14, 2017

pISSN 1976-2283 eISSN 2005-1212 https://doi.org/10.5009/gnl16500

@) This is an Open Access article distributed under the terms of the Creative Commons Attribution Non-Commercial License (http://creativecommons.org/licenses/by-nc/4.0) which permits unrestricted non-commercial use, distribution, and reproduction in any medium, provided the original work is properly cited. 
CONNECT study, a nationwide cohort study consisting of 1,352 patients with CD from 32 institutions in Korea, reported various clinical outcomes such as the clinical characteristics of patients with free perforation and factors related to diagnostic delay. ${ }^{11,12}$

This study aimed to evaluate the prognosis of patients with CD who showed involvement of the proximal small bowel, and to identify whether proximal small bowel involvement was associated with upper gastrointestinal involvement in these patients.

\section{MATERIALS AND METHODS}

\section{Patients}

We analyzed data from the CONNECT study, ${ }^{13}$ a retrospective multicenter cohort study that enrolled patients who were diagnosed as having CD between 1982 and 2008 from 32 IBD centers in Korea. Patients' conditions were diagnosed based on clinical symptoms, endoscopy (esophagogastroduodenoscopy, colonoscopy, capsule endoscopy, or enteroscopy) findings, radiological imaging study (abdominal computed tomography [CT] scan, magnetic resonance imaging, or small bowel series) findings, and pathological examination results. The study was approved by the institutional review boards of all participating hospitals.

\section{Measurements}

The following demographic information was obtained: patient age, sex, family history of inflammatory bowel disease, smoking status, disease characteristics such as location and behavior of the disease, presence of perianal fistulas, and surgical or other treatment methods used. CD was diagnosed according to the Korean diagnostic guidelines for $\mathrm{CD} .{ }^{14}$ Disease location and behavior at initial presentation were classified according to the Montreal classification. ${ }^{15}$ The medications used for treatment of CD (e.g., azathioprine, corticosteroids, and tumor necrosis factor [TNF]- $\alpha$ blocker) were also reviewed. In addition, patients who underwent CD-related surgery were identified and the surgeryfree survival rate was calculated. Surgery was defined as any major gastrointestinal operation including colectomy and small bowel resection. Surgery-free survival was defined as the time interval between the diagnosis of $\mathrm{CD}$ and the first CD-related surgery.

Patients with CD who showed proximal small bowel involvement were identified to establish whether the involvement was associated with involvement of the upper gastrointestinal tract. Proximal small bowel involvement was determined by at least one of the following small-bowel modalities: small-bowel follow-through (SBFT), CT enterography, capsule endoscopy, or double-balloon enteroscopy. Patients who did not undergo any of the aforementioned imaging modalities were assumed to not show proximal small bowel involvement, based on the findings of conventional abdominal CT scan. In addition, upper gastro- intestinal involvement was assessed via endoscopic findings, which included mucosal ulceration, cobblestoning, stricture, or bowel wall thickening.

\section{Statistical analysis}

Continuous variables are expressed as mean and standard deviation, and categorical variables are expressed as number and proportion. Baseline characteristics of patients were compared using the t-test for continuous variables and chi-square test for categorical variables. Surgery free-survival according to disease location was evaluated via Kaplan-Meier plots and logrank tests. To adjust the possible confounding variables, a Cox proportional hazards model was used. Additionally, any factors that associated CD with upper gastrointestinal involvement were analyzed using logistic regression analysis. A p-value $<0.05$ was considered statistically significant. All statistical procedures were conducted using the statistical software SPSS for Windows version 12.0 (SPSS Inc., Chicago, IL, USA), with the exception of the survival analysis, which was performed using R software version 2.15.3 (R Foundation for Statistical Computing, Vienna, Austria).

\section{RESULTS}

\section{Baseline characteristics of patients}

Of the 1,352 patients in the CONNECT study, 23 had insufficient data about the disease location and were excluded. As a result, 1,329 patients were included in this study. Of these, 222 patients (16.7\%) showed proximal small bowel involvement (Table 1). The median follow-up duration was 68.2 months (interquartile range [IQR], 9.9 to 104.3 months) and 72.2 months (IQR, 25.9 to 104.5 months) in patients with and without proximal small bowel involvement, respectively.

Age and sex did not differ between the two groups (proximal small bowel involvement vs without involvement: age, $27.5 \pm 12.1$ years vs $27.7 \pm 12.2$ years, $p=0.768$; male, $73.0 \%$ vs $70.0 \%, p=0.377$ ). Smoking history was more common in the proximal small bowel involvement group than without involvement (involvement vs noninvolvement: smoker, 18.9\% vs $14.2 \%$; non-smoker, $45.5 \%$ vs $54.6 \%$; unknown, $35.6 \%$ vs $31.3 \% ; p=0.035$ ). Additionally, disease location depended on the presence of proximal small bowel involvement (involvement vs noninvolvement: L1, 31.5\% vs 21.0\%; L2, 2.7\% vs 19.2\%; L3: $63.5 \%$ vs $59.4 \%$; $44,2.3 \%$ vs $0.3 \%$; $<0.001$ ). Perianal fistula was less common at the time of diagnosis in the proximal small bowel involvement group than without involvement group (20.7\% vs 28.3\%, p=0.020). Patients with proximal small bowel involvement showed a more complicated (stricturing) disease behavior than that shown by patients without involvement (involvement vs noninvolvement: B1, 71.6\% vs 78.6\%; B2, 19.8\% vs $12.7 \%$; $\mathrm{B} 3$, $8.6 \%$ vs $8.7 \%$; $\mathrm{p}=0.020$ ). 
Table 1. Baseline Patient and Lesion Characteristics

\begin{tabular}{|c|c|c|c|}
\hline Variable & $\begin{array}{l}\text { Proximal small bowel involvement } \\
\qquad(\mathrm{n}=222)\end{array}$ & $\begin{array}{l}\text { Proximal small bowel noninvolvement } \\
\qquad(\mathrm{n}=1,107)\end{array}$ & p-value \\
\hline Age, yr & $27.5 \pm 12.1$ & $27.7 \pm 12.2$ & 0.768 \\
\hline Male sex & $162(73.0)$ & 775 (70.0) & 0.377 \\
\hline Family history of IBD & & & 0.822 \\
\hline Presence & $6(2.7)$ & $24(2.2)$ & \\
\hline Absence & $203(91.4)$ & $1,010(91.2)$ & \\
\hline Unknown & $13(5.9)$ & $73(6.6)$ & \\
\hline Smoking & & & 0.035 \\
\hline Smoker & $42(18.9)$ & $157(14.2)$ & \\
\hline Non-smoker & $101(45.5)$ & $604(54.6)$ & \\
\hline Unknown & 79 (35.6) & $346(31.3)$ & \\
\hline Disease location & & & $<0.001$ \\
\hline L1 & $70(31.5)$ & $233(21.0)$ & \\
\hline L2 & $6(2.7)$ & $213(19.2)$ & \\
\hline L3 & $141(63.5)$ & $658(59.4)$ & \\
\hline L4 & $5(2.3)$ & $3(0.3)$ & \\
\hline Upper gastrointestinal involvement & $24(10.8)$ & $76(6.9)$ & 0.042 \\
\hline Perianal fistula at diagnosis & $46(20.7)$ & $313(28.3)$ & 0.020 \\
\hline Disease behavior & & & 0.020 \\
\hline B1 & 159 (71.6) & 870 (78.6) & \\
\hline B2 & $44(19.8)$ & 141 (12.7) & \\
\hline B3 & $19(8.6)$ & $96(8.7)$ & \\
\hline \multicolumn{4}{|l|}{ Medication } \\
\hline Azathioprine & $156(70.3)$ & $713(64.4)$ & 0.094 \\
\hline Corticosteroid & 135 (60.8) & 677 (61.2) & 0.923 \\
\hline TNF- $\alpha$ blocker & 67 (30.2) & 310 (28.0) & 0.511 \\
\hline
\end{tabular}

Data are presented as mean \pm SD or number $(\%)$.

IBD, inflammatory bowel disease; L1, ileal location; L2, colonic location; L3, ileocolonic location; L4, proximal disease; B1, non-stricturing, nonpenetrating; B2, stricturing; B3, penetrating; TNF, tumor necrosis factor.

\section{Association between proximal small bowel involvement and need for surgery}

Surgery-free survival was inferior in patients with proximal small bowel involvement compared to that in patients without proximal small bowel involvement (10-year surgery-free survival: $58.4 \%$ [95\% confidence interval (CI), $51.1 \%$ to $66.6 \%]$ vs $67.7 \%$ [95\% CI, 64.2\% to 71.3\%], respectively, p<0.001) (Fig. 1).

After adjusting for possible confounding variables, such as age, sex, and perianal fistulas, medications including azathioprine, corticosteroid, and TNF- $\alpha$ blockers, and upper gastrointestinal involvement, proximal small bowel involvement was found to be an independent risk factor for surgery after the diagnosis of CD (hazard ratio [HR], 1.507; 95\% CI, 1.170 to 1.941). In addition to proximal small bowel involvement, female sex, complicated disease behavior (B2, B3), and use of azathioprine were poor prognostic factors in terms of surgery-free survival

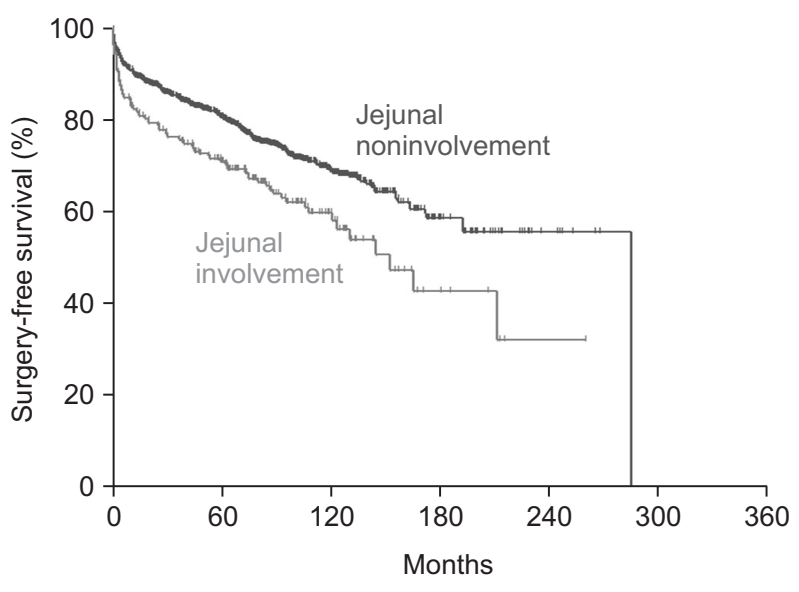

Fig. 1. The surgery-free survival of patients with Crohn's disease according to proximal small bowel involvement. 
(female sex: HR, 1.316; 95\% CI, 1.051 to 1.647 ; stricturing behavior: HR, 1.373; 95\% CI, 1.033 to 1.826 ; penetrating behavior: HR, 2.114; 95\% CI, 1.536 to 2.910; azathioprine: HR, 1.354; 95\% CI, 1.053 to 1.742 ).

\section{Risk factor for upper gastrointestinal involvement}

On univariable analysis, proximal small bowel involvement was the only factor associated with upper gastrointestinal involvement $(\mathrm{p}=0.042)$. However, smoking history and perianal fistula tended to be associated with upper gastrointestinal involvement ( $\mathrm{p}=0.160$ and $\mathrm{p}=0.106$, respectively). Multivariate analysis also showed a significant relationship between involvement of the proximal small bowel and the upper gastrointestinal tract (odds ratio, 1.643; 95\% CI, 1.008 to 2.677), while smoking history and perianal fistulas did not (Table 2).

\section{DISCUSSION}

Clinically, it is important to understand the prognostic factors associated with CD-related surgical complications for the management of patients with $\mathrm{CD}$. It has been shown that early immunosuppression, rather than an escalation strategy, may help to improve the mucosal healing rate in patients with moderateto-severe $\mathrm{CD} .{ }^{16}$ Identification of high-risk patients who would require surgical intervention to treat $\mathrm{CD}$-related complications will lead to proper use of biologic agents.

In this study, complicated disease behavior as well as proximal small bowel involvement was associated with poor surgeryfree survival. In other words, in addition to patients who show complicated disease, those with proximal small bowel involvement should be considered as high risk in terms of CD-related surgery. Aggressive medical therapy, which is provided to patients with complicated disease behavior, should also be actively considered in patients with proximal small bowel involvement. Patients with CD can be risk-stratified based on the two highly predictive risk factors identified by our study as follows: (1) high risk (demonstrating both complicated disease behavior and proximal small bowel involvement); (2) moderate risk (demon-

Table 2. Factors Associated with Upper Gastrointestinal Involvement of Crohn's Disease

\begin{tabular}{|c|c|c|c|c|c|}
\hline \multirow{2}{*}{ Variable } & \multirow{2}{*}{ No. } & \multirow{2}{*}{$\begin{array}{l}\text { Upper gastrointestinal } \\
\text { involvement, no. }(\%)\end{array}$} & \multirow{2}{*}{$\begin{array}{c}\text { Univariable } \\
\text { analysis }\end{array}$} & \multicolumn{2}{|c|}{ Multivariable analysis } \\
\hline & & & & OR $(95 \% \mathrm{CI})$ & $\mathrm{p}$-value \\
\hline Age, yr & 1,329 & NA & 0.833 & $1.004(0.986-1.022)$ & 0.660 \\
\hline Sex & & & 0.305 & & \\
\hline Male & 937 & $75(8.0)$ & & $1.129(0.691-1.846)$ & 0.629 \\
\hline Female & 392 & $25(6.4)$ & & 1.000 & \\
\hline Family history of IBD & & & 0.961 & & \\
\hline Presence & 30 & $2(6.7)$ & & & \\
\hline Absence & 1,213 & $91(7.5)$ & & & \\
\hline Unknown & 86 & $7(8.1)$ & & & \\
\hline Smoking & & & 0.160 & & \\
\hline Smoker & 199 & $21(10.6)$ & & $1.541(0.874-2.716)$ & 0.135 \\
\hline Non-smoker & 705 & $46(6.5)$ & & 1.000 & \\
\hline Unknown & 425 & $33(7.8)$ & & $1.171(0.733-1.871)$ & 0.509 \\
\hline Perianal fistula at diagnosis & & & 0.104 & & \\
\hline Presence & 360 & $34(9.5)$ & & $1.485(0.950-2.323)$ & 0.083 \\
\hline Absence & 969 & $66(6.8)$ & & 1.000 & \\
\hline Disease behavior & & & 0.381 & & \\
\hline B1 & 1,029 & $72(7.0)$ & & & \\
\hline B2 & 185 & $18(9.7)$ & & & \\
\hline B3 & 115 & $10(8.7)$ & & & \\
\hline Proximal small bowel involvement & & & 0.042 & & \\
\hline Presence & 222 & $24(10.8)$ & & $1.643(1.008-2.677)$ & 0.046 \\
\hline Absence & 1,107 & $76(6.9)$ & & 1.000 & \\
\hline
\end{tabular}

Age, sex, smoking, perianal fistula at diagnosis, and proximal small bowel involvement were included in the multivariable analysis. $\mathrm{OR}$, odds ratio; CI, confidence interval; NA, not available; IBD, inflammatory bowel disease; B1, non-stricturing, non-penetrating; B2, stricturing; $\mathrm{B} 3$, penetrating. 
strating either complicated disease behavior or proximal small bowel involvement); and (3) low risk (demonstrating neither complicated disease behavior nor proximal small bowel involvement). High, moderate, and low risk categories constituted 63 (4.7\%), 396 (29.8\%), and 870 (65.5\%) of our study participants, respectively. We hope to test and validate the use of this risk stratification system in the selection of optimal treatment strategies in a subsequent study.

These findings could help us predict the poor prognostic factors according to the involvement of the proximal small bowel. In a previous study, it was shown that patients with $\mathrm{CD}$ who showed proximal small bowel involvement had more frequent relapse and more chances of requiring surgery. ${ }^{2,17}$ The main cause of the poor prognosis may be extensive disease involvement. In our study, the proportion of ileal involvement (L1 and L3) was higher in patients with proximal small bowel involvement than in those without small bowel involvement. Upper gastrointestinal involvement was more common in patients with proximal small bowel involvement than in those without proximal small bowel involvement. More extensive disease may lead to more stricturing (B2) and requirement of surgery. However, the exact pathogenesis of $\mathrm{CD}$ in patients showing proximal small bowel involvement should be investigated in detail.

The proportion of patients with proximal small bowel involvement was $16.7 \%$ in our study, compared to 3.8\% in Western countries. ${ }^{17}$ This result is similar to another Korean study that estimated it at $14.1 \% .{ }^{18}$ Genetic or environmental factors have been suggested as possible reasons for this discrepancy. Previous reports have suggested a difference in the genetic susceptibility for inflammatory bowel disease between Asian and Western populations. ${ }^{19,20}$ Considering that compared to patients with CD in Western countries, those in Korea show a higher proportion of proximal small bowel involvement, proximal small bowel involvement may have an important role as a prognostic indicator in $\mathrm{CD}$ and, therefore, should be considered in the clinical management of patients with $\mathrm{CD}$.

We also revealed a connection between proximal small bowel involvement and upper gastrointestinal involvement. There appears to be a much more widespread disease burden if proximal small bowel involvement is identified via imaging studies such as CT scan. Patients with proximal small bowel involvement should be evaluated for upper gastrointestinal involvement via upper endoscopy. Conversely, patients diagnosed with CD via upper gastrointestinal endoscopy should also be assessed for proximal small bowel involvement. A precise evaluation of the disease extent at the time of the initial diagnosis may help to predict the prognosis, including surgery-free survival.

Although this study showed the characteristics and prognosis of patients with $\mathrm{CD}$ who showed proximal small bowel involvement, from a multicenter nation-wide cohort, it has several limitations. First, the cohort was established via retrospective review. Although the prescribed treatment plans were largely based on established guidelines, a detailed, standardized treatment protocol was not used. Standardization of the treatment method and prospective data collection may be necessary to reach a definitive conclusion. In addition, several confounding variables including inflammatory markers and nutritional status could not be evaluated owing to the retrospective design of the study. A future prospective observational study may be required to arrive at a definitive conclusion. Second, proximal small bowel involvement was not fully evaluated in some patients. Although most of the patients underwent imaging studies for small bowel evaluation including SBFT, CT enterography, capsule endoscopy, and double-balloon enteroscopy, those who did not undergo any imaging study were assumed to not show proximal small bowel involvement, based on the findings of conventional abdominal CT scan. Third, we did not assess the quality of life of patients who underwent surgery. Compared to a relatively simple surgery, extensive bowel resection and repeat surgeries may worsen the quality of life. Therefore, the prognosis of patients who undergo extensive surgery and those who undergo simple surgery should not be equated. Although we demonstrated that patients with proximal small bowel involvement had inferior surgery-free survival, the quality of life of these patients should be assessed in a future study. Fourth, although we captured an important disease phenomenon, we were unable to offer a plausible explanation for it. We failed to clarify whether the extent of the disease or the different biological characteristics of patients with and without proximal small bowel involvement should garner greater concern. ${ }^{3}$ The mechanism underlying the poor surgery-free survival in patients with proximal small bowel involvement should be explored.

Despite these limitations, our multicenter nationwide cohort data provided a better understanding of the clinical characteristics and prognosis of Korean patients with CD who showed proximal small bowel involvement, which was a poor prognostic factor for surgery-free survival. Upper endoscopy is highly warranted for the evaluation of disease location and prognosis of patients with $\mathrm{CD}$.

\section{CONFLICTS OF INTEREST}

No potential conflict of interest relevant to this article was reported.

\section{ACKNOWLEDGEMENTS}

This work was supported by a research program funded by the Korean Centers for Disease Control and Prevention (2016E63001-00) and a Grant of the Korean Health Technology R\&D Project, Ministry of Health \& Welfare, Republic of Korea (A120176) (D.S.H.). 


\section{REFERENCES}

1. Freeman HJ. Natural history and long-term clinical course of Crohn's disease. World J Gastroenterol 2014;20:31-36.

2. Keh C, Shatari T, Yamamoto T, Menon A, Clark MA, Keighley MR. Jejunal Crohn's disease is associated with a higher postoperative recurrence rate than ileocaecal Crohn's disease. Colorectal Dis 2005;7:366-368.

3. Lazarev M, Huang C, Bitton A, et al. Relationship between proximal Crohn's disease location and disease behavior and surgery: a cross-sectional study of the IBD Genetics Consortium. Am J Gastroenterol 2013;108:106-112.

4. Peyrin-Biroulet L, Loftus EV Jr, Colombel JF, Sandborn WJ. The natural history of adult Crohn's disease in population-based cohorts. Am J Gastroenterol 2010;105:289-297.

5. Jess T, Riis L, Vind I, et al. Changes in clinical characteristics, course, and prognosis of inflammatory bowel disease during the last 5 decades: a population-based study from Copenhagen, Denmark. Inflamm Bowel Dis 2007;13:481-489.

6. Thia KT, Sandborn WJ, Harmsen WS, Zinsmeister AR, Loftus EV Jr. Risk factors associated with progression to intestinal complications of Crohn's disease in a population-based cohort. Gastroenterology 2010;139:1147-1155.

7. Molodecky NA, Soon IS, Rabi DM, et al. Increasing incidence and prevalence of the inflammatory bowel diseases with time, based on systematic review. Gastroenterology 2012;142:46-54.e42.

8. Goh K, Xiao SD. Inflammatory bowel disease: a survey of the epidemiology in Asia. J Dig Dis 2009;10:1-6.

9. Ng WK, Wong SH, Ng SC. Changing epidemiological trends of inflammatory bowel disease in Asia. Intest Res 2016;14:111-119.

10. Yang SK, Yun S, Kim JH, et al. Epidemiology of inflammatory bowel disease in the Songpa-Kangdong district, Seoul, Korea, 1986-2005: a KASID study. Inflamm Bowel Dis 2008;14:542-549.
11. Doh YS, Kim YS, Bae SI, et al. The clinical characteristics of patients with free perforation in Korean Crohn's disease: results from the CONNECT study. BMC Gastroenterol 2015;15:31.

12. Moon CM, Jung SA, Kim SE, et al. Clinical factors and disease course related to diagnostic delay in Korean Crohn's disease patients: results from the CONNECT study. PLoS One 2015;10:e0144390.

13. Cheon JH, Kim YS, Ye BD, et al. Crohn's Disease Clinical Network and Cohort (CONNECT) study: the first step toward nationwide multicenter research of Crohn's disease in Korea. Intest Res 2014; 12:173-175.

14. Ye BD, Jang BI, Jeen YT, et al. Diagnostic guideline of Crohn's disease. Korean J Gastroenterol 2009;53:161-176.

15. Silverberg MS, Satsangi J, Ahmad T, et al. Toward an integrated clinical, molecular and serological classification of inflammatory bowel disease: report of a Working Party of the 2005 Montreal World Congress of Gastroenterology. Can J Gastroenterol 2005;19 Suppl A:5A-36A.

16. Kang B, Choi SY, Kim HS, Kim K, Lee YM, Choe YH. Mucosal healing in paediatric patients with moderate-to-severe luminal Crohn's disease under combined immunosuppression: escalation versus early treatment. J Crohns Colitis 2016;10:1279-1286.

17. Freeman HJ. Long-term clinical behavior of jejunoileal involvement in Crohn's disease. Can J Gastroenterol 2005;19:575-578.

18. Park SK, Yang SK, Park SH, et al. Long-term prognosis of the jejunal involvement of Crohn's disease. J Clin Gastroenterol 2013;47:400-408.

19. Thia KT, Loftus EV Jr, Sandborn WJ, Yang SK. An update on the epidemiology of inflammatory bowel disease in Asia. Am J Gastroenterol 2008;103:3167-3182.

20. Hu PJ. Inflammatory bowel disease in Asia: the challenges and opportunities. Intest Res 2015;13:188-190. 